\title{
Algunas consideraciones acerca de la educación ambiental no formal (Nota técnica)
}

\author{
Some considerations about environmental \\ not formal education (Technical note)
}

Jorge Villadiego-Lorduy'

Dennis Huffman-Schwocho²

Adolfo Cortecero-Bossio ${ }^{3}$

Richard Ortiz-Sánchez ${ }^{4}$

Fecha de recepción: 21 de enero del 2014

Fecha de aprobación: 27 de abril del 2014

Villadiego-Lorduy, j; Huffman-Schwocho, D;

Cortecero-Bossio, A; Ortiz-Sánchez, R. Algunas

consideraciones acerca de la educación ambiental

no formal. Tecnología en Marcha. Vol. 27, N 3,

Julio-Setiembre 20|4. Pág |36-|46.

I Geógrafo. Estudiante del programa de Doctorado en Ciencias Naturales para el Desarrollo. Instituto Tecnológico de Costa Rica. Costa Rica. Correo electrónico: villalordI5@yahoo.es. Teléfono: 3|3 505 8I80. Fundación Salud Mental para Todos. Departamento de Córdoba, Montería, Colombia.

2 Doctor en Pedagogía. Profesor titular del programa de Doctorado en Ciencias Naturales para el Desarrollo. Instituto Tecnológico de Costa Rica. Costa Rica Teléfono: (506) 2475-53I0. Correo electrónico: d_huffman@yahoo.com.

3 Ingeniero Químico. Máster en Gestión Ambiental. Teléfono: 3|45346748. Correo electrónico: acobo7|@yahoo.com. Fundación Kontiqui. Departamento de Bolívar, Cartagena de Indias, Colombia.

4 Ingeniero Ambiental. Estudiante del programa de Doctorado en Ciencias Naturales para el Desarrollo. Instituto Tecnológico de Costa Rica. Teléfono: 3116752888. Correo electrónico: richarortizsanchez@hotmail.com. Consejo noruego para refugiados. Departamento de Santander, Ocaña, Colombia. 


\section{Palabras clave}

Capitalismo; sociedad de consumo; modelo educativo; desarrollo sostenible.

\section{Resumen}

El propósito de este documento es debatir sobre las diversas concepciones de la educación ambiental no formal, así como el desarrollo de una apreciación del modelo económico actual basado en la superproducción y superconsumo para unos pocos y la escasez para la mayoría; sin omitir la diferenciación entre crecimiento, desarrollo económico y sostenible. Se analizan algunos trabajos y experiencias con respecto a la educación ambiental no formal en Latinoamérica, así como varios de los factores que no favorecen la implementación de este tipo de procesos educativos. Por último, se definen algunos elementos de manera general sobre los que se podría estructurar un modelo de educación ambiental no formal y participativa, además se incluyen conclusiones y recomendaciones.

\section{Key words}

Capitalism; consumer society; educational model; sustainable development.

\begin{abstract}
The purpose of this paper is to discuss the various conceptions of non-formal environmental education as well as developing an appreciation of the current economic model based on overproduction and overconsumption to a few and scarce for most, without omitting the distinction between growth and sustainable economic development. An analysis of some jobs or experiences delivered in non-formal environmental education at Latin America, as well as factors that do not favor the implementation of processes in non-formal environmental education is established. Finally, some general elements on which a model could be structured and participatory non formal environmental education are defined. Like some conclusions and recommendations on the issue.
\end{abstract}

\section{Introducción}

La problemática ambiental se ha acelerado y agudizado en las últimas décadas; hoy día la globalización económica impone nuevas pautas para la producción y consumo de recursos. Por lo tanto, la educación es una vía útil y necesaria para potenciar al máximo la formación y capacitación ambiental en distintos ámbitos de la sociedad, desde quienes tienen en sus manos la toma de decisiones importantes hasta los niveles ciudadanos, en los que la actuación diaria incide en forma directa sobre el medio (Novo, 1998).

Los orígenes de la educación ambiental se sitúan en los años 70, aunque el término educación ambiental ya aparece en documentos de la Organización de las Naciones Unidas para la Educación, la Ciencia y la Cultura (UNESCO) de 1965. Sin embargo, no es sino hasta 1972, durante la Conferencia de las Naciones Unidas sobre el Medio Humano, en Estocolmo, que se reconoce oficialmente la existencia de este concepto y su importancia para cambiar el modelo de desarrollo. Desde entonces se han realizado diferentes eventos que han ido conformando el llamado debate ambiental, entre los que se destacan el Coloquio Internacional sobre la Educación relativa al Medio Ambiente (Belgrado, 1975), en el que se definieron los objetivos y líneas de acción de la educación ambiental; igualmente importante fue la Conferencia Intergubernamental sobre Educación Ambiental, organizada por la UNESCO y el Programa de las Naciones Unidas para el Medio Ambiente (PNUMA) en Tiflis (antigua URSS, 1977), que planteó la incorporación de la educación ambiental en los sistemas educativos de los estados participantes, concretando sus funciones y principios, así como el diseño y elaboración de material de educación ambiental y la participación activa de los ciudadanos en todos los niveles sociales.

Cabe resaltar que es en 1967, en la Conferencia Internacional sobre la Crisis Mundial de la Educación, en Williamsburg (Virginia, Estados Unidos), que P. Coombs (citado por Camors, 2009), Director del Instituto Internacional de Planeamiento de la 
Educación de la UNESCO, plantea "un énfasis especial en la necesidad de desarrollar medios educativos diferentes a los convencionalmente escolares". A partir de este momento comienza el uso de denominaciones tales como "informal" $y$ "no formal" para dar cuenta del "amplísimo y heterogéneo abanico de procesos educativos no escolares o situados al margen del sistema de la enseñanza reglada (p. 24).

\section{La educación ambiental}

La educación ambiental (EA) hoy día se ha convertido en un poderoso instrumento de la gestión ambiental y debe entenderse como un proceso dinámico y participativo, que busca despertar en la población una conciencia que le permita identificarse con esta problemática tanto a nivel general como individual. Guier (2002) define la EA como "un proceso inherente a todo espacio educativo, conducente a la formación de personas despiertas a su realidad y conscientes de que pertenecen a un sistema ecológico global, regido por una serie de leyes y principios que deben conocerse y sobe todo, respetarse para garantizar la vida misma" (pp. 2-3). Por otra parte, la educación ambiental se divide en tres categorías: formal, no formal e informal. La primera está inmersa en el sistema educativo tradicional y organizada en un currículo de carácter transversal. La segunda se fundamenta en la transmisión de conocimientos, aptitudes y valores ambientales fuera del sistema educativo tradicional que conducen a que las personas beneficiarias de este tipo de educación desarrollen aptitudes positivas con el ambiente; su fin no es alcanzar certificaciones o títulos. La última y no menos importante, la informal, se da de forma espontánea, no planificada y no responde a estructuras pedagógicas.

En el mismo sentido, Bohm (citado por Guier, 2002) establece unos principios que caracterizan la EA y su implementación, basados en el enfoque sistémico e interdisciplinar, resolución de problemas, metodología participativa, reconocimiento de la biodiversidad y de la sociodiversidad, solidaridad, pensamiento constructivo y enfoque interpretativo. Covas (2004) apunta a varios de estos principios y enfatiza la pertinencia de que la educación ambiental se trabaje bajo tres enfoques: comunitario, sistémico e interdisciplinario. Desde el enfoque comunitario, se hace necesario involucrar a las personas en el análisis de los problemas ambientales de sus territorios, generar pensamientos desde lo local hacia lo global con el fin de proponer alternativas de solución. El enfoque sistémico da herramientas para analizar la realidad de forma holística; aquellas personas que son capacitadas con una comprensión sistémica de la complejidad ambiental, que participan en el ámbito comunitario, son capaces de diseñar futuros posibles y deseables. Asimismo, la interdisciplinariedad permite hacer aportaciones desde las diferentes áreas del saber de forma articulada.

\section{Educación ambiental no formal}

Generalmente, cuando hablamos de educación, lo primero que pensamos es en la escuela. La educación ha sido limitada a escolaridad y descartamos o restamos importancia a otras prácticas, espacios y escenarios sociales que son tanto o más importantes para la formación de las personas (Buenfil et al., |99|). Para Gonzáles (1993), la educación no formal (ENF) es aquella que se desarrolla paralela o independiente de la educación formal y por tanto no queda inscrita en los programas del ciclo del sistema escolar y aunque las experiencias educativas sean secuenciales, no se acredita y no se certifica.

En 1974 Coombs y Ahmed (citados por Camors, 2009) proponen una distinción conceptual entre educación formal, no formal e informal. Llamaban educación no formal a "toda actividad organizada, sistemática, educativa, realizada fuera del marco del sistema oficial, para facilitar determinadas clases de aprendizajes a subgrupos particulares de la población, tanto adultos como niños" (p. 24). En el mismo sentido, Trilla (1996) afirma que la educación no formal es una modalidad de la educación. El concepto surge históricamente ante los problemas y dificultades del desarrollo de la escolarización, como una forma de alcanzar los objetivos educativos propuestos para toda la población. Surge precisamente para completar, reforzar, o continuar, en su caso, suplir ciertos cometidos escolares.

Por otra parte, la educación no formal enfrenta una serie de desafíos que debe superar con el fin de hacer mucho más efectiva su implementación. La UNESCO y el Ministerio de Educación y Cultura de Uruguay (2009) formularon el documento titulado Aportes para la Elaboración de Políticas Educativas, en el cual se planten una serie de desafíos, señalándose: 
I) La re/construcción de una pedagogía que rescate, de sus orígenes, la posibilidad de reflexionar sobre el hecho educativo, donde sea que aquel suceda.

2) La formulación de indicadores que nos permitan reconocer los procesos y logros educativos que alcanzan los participantes.

3) La construcción de un perfil de educador apropiado a estas circunstancias, para actuar con fundamentos, intencionalidad, metodología apropiada y capacidad de adaptación de la propuesta educativa a los diferentes contextos sociales y culturales.

Pacheco (s. f.) esboza una serie de ámbitos de la ENF, que van desde las funciones relacionadas con educación formal, trabajo, ocio y formación cultural hasta vida cotidiana y social. En términos de educación formal, se le asocia a programas de alfabetización de adultos y de la oferta de actividades y recursos fuera de la educación formal. Para el segundo ámbito, trabajo, está relacionada con formaciones a nivel sindical, de extensión agrícola y ocupacional. En cuanto al ocio y formación cultural, éstas abarcan actividades de educación artística, deportiva, cultural y pedagógica de tiempo libre. Para la vida cotidiana y social se cuenta con programas de cualificación sanitaria, padres y economía doméstica. También el mismo autor relaciona los enfoques centrales dentro de la ENF, que básicamente se resumen en educación para adultos, desarrollo comunitario, centro cultural y asociacionismo.

En el marco de la educación ambiental, la no formal (EANF) busca generar en individuos o comunidades actitudes o acciones positivas hacia el entorno en que habitan, a partir de la reflexión sobre los impactos negativos que estos y éstas ocasionen al medio en su diario vivir, y fuera de un sistema educativo riguroso o formal. Guier (2002) indica que la educación ambiental no formal es responsabilidad de organizaciones gubernamentales y no gubernamentales, además prioriza las capacitaciones y producción de materiales didácticos. El grupo meta se define según los objetivos del programa o modelo a implementar y existe una relación estrecha en que también se contemplan los sistemas a distancia. Al respecto, Novo (2005) señala una serie de características que se encuentran implícitas en este tipo de educación, como son el contexto, el desarrollo de procesos interdisciplinares, la conciencia participativa, la flexibilización del rol profesor/estudiante, la creación de redes, los múltiples recursos y vías de aprendizaje y la estimulación de relaciones de educación/ trabajo. Igualmente, el mismo autor enfatiza en los principios y valores que fundamentan la educación ambiental no formal, como también en el concepto de interdependencia entre las esferas social, económica y natural, con el fin de entender el planeta como una unidad y generar pensamientos globales pero con actuaciones locales. La fuerza de la educación ambiental no formal reside en el hecho de que no opera dentro de un conjunto dado de reglas con estructura estricta, currículo y procedimiento de exámenes, sino que tiene mayor capacidad de responder a los temas ambientales locales, que poseen mayor significado social y utilidad para la comunidad y están menos dominados por temas académicos.

\section{El modelo económico actual}

Creer que el modelo económico capitalista encaja o se encuentra en simbiosis con el componente natural del planeta es una gran falacia; tanto economistas como ambientalistas, gobiernos y hasta algunos ciudadanos de a pie se cuestionan sobre la viabilidad a futuro del actual sistema económico y del planeta. Básicamente un sistema de producción consta de los siguientes elementos: (I) materias primas necesarias para su transformación, (2) procesos de transformación que genere un valor agregado a la materia prima y (3) salida de bienes, servicios y desechos (ver figural).

La figura I muestra de forma esquemática cómo funciona el sistema capitalista, el cual presenta una demanda constante de materias primas, que son suministradas por los ecosistemas para generar procesos productivos; como resultado, se obtienen bienes y servicios y una gran cantidad de desechos que son asimilados por el planeta, que además presta el servicio de sumidero. Uno de los problemas del modelo capitalista radica en que la demanda por recursos naturales es mayor que la capacidad regenerativa de los ecosistemas, lo cual ha llevado a que se sobrepasen los límites ecológicos del planeta. En consecuencia, se tiene un sistema económico donde los ecosistemas están en función del mismo, sin importar la capacidad regenerativa de éstos. Lo adecuado sería generar un modelo de producción sostenible que esté en función de los ecosistemas y que tenga 
como prioridad respetar la capacidad regenerativa de la naturaleza y sus límites (ver figura 2).

La insostenibilidad ambiental existente hoy día producto del capitalismo salvaje se ha concretado en una marcada brecha social, deterioro ambiental y una sociedad de consumo insaciable donde lo realmente importante es consumir, no importa qué. El bombardeo constante de publicidad a través de los medios de comunicación masiva invita a las personas a consumir productos que muchas veces ni siquiera les son de utilidad. Por otra parte, los productos y servicios poseen un ciclo de vida demasiado corto, "obsolescencia programada", aumentando el volumen de desechos en el planeta. Para Meira (2006), la principal consecuencia de la globalización es la conversión de todo el planeta en objeto de los intereses de una civilización, la occidental, que ha convertido en hegemónicos su modelo de producción-consumo y las estructuras políticas y patrones culturales que lo aderezan y legitiman. La fase actual de este proceso, la globalización, sería una forma de neocolonialismo más sutil y sofisticada que la denunciada en los años 60 y 70 del siglo pasado: aparecen nuevos instrumentos que aceleran e integran cada vez más los flujos económicos -las nuevas tecnologías de la comunicación y del transporte-, nuevas formas de reproducción del capital-dominadas por la economía especulativa- y nuevas estrategias de producción -la deslocalización de las actividades productivas en busca de bajos salarios, menor presión fiscal y un control ambiental más laxo- (p. I I I).

\section{Crecimiento, desarrollo y} desarrollo sostenible

Existe una gran diferencia entre crecimiento y desarrollo; el primero está asociado a un orden de tipo cuantitativo, acumulación de materiales,

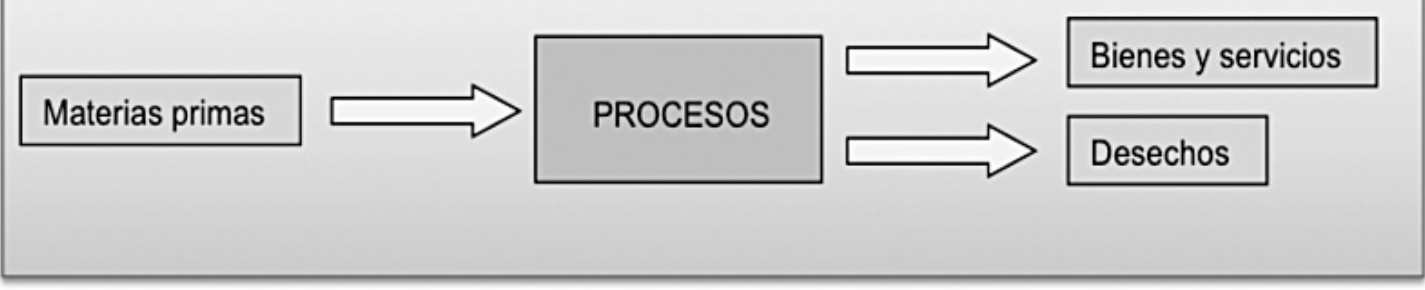

Figura I. Elementos de un sistema de producción. Fuente: Elaboración propia.
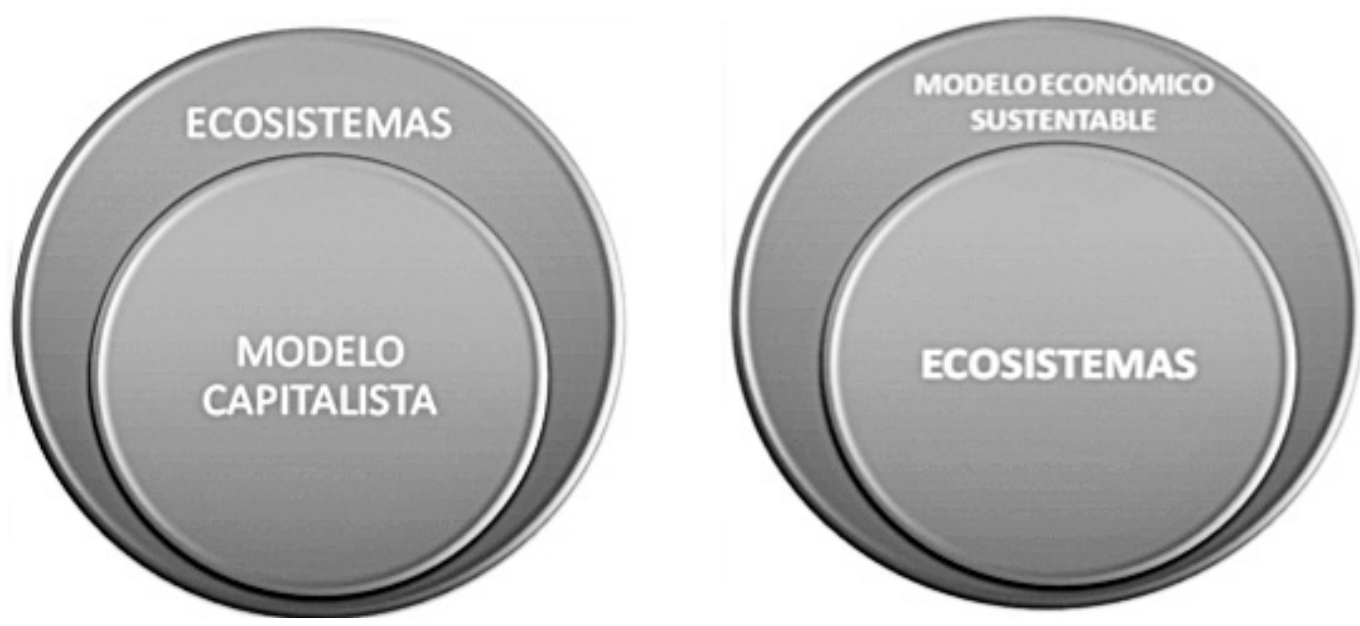

Figura 2. Esquema modelo económico capitalista vs modelo económico sostenible. Fuente: Elaboración propia. 
aumento en la producción real. El desarrollo está más enfocado en concretar las potencialidades de un territorio, de comunidades, individuos, etc. El ciudadano común tiende a confundir ambos conceptos, por ejemplo, cree que si en su territorio se construyen puentes, se pavimentan calles y aumenta la edificación es porque su ciudad se está desarrollando, para él no importa si los índices de pobreza y miseria aumentan, si hay bajos niveles de ingresos, si cada vez hay menos empleos o se incrementa la violencia, el crecimiento urbanístico arriba mencionado lo asocia al desarrollo de su municipalidad. Sen (citado por Arribas, 2007) afirma al respecto: "Convencionalmente, se tiende a identificar el desarrollo con la satisfacción de necesidades biológicas universales como el alimento o el cobijo. Pero estas son realmente condiciones favorables para el desarrollo de capacidades como la libertad, la autonomía individual, la posibilidad de hacer contribuciones significativas a la sociedad, la adquisición de conocimiento y habilidades, el sentido estético y facultades morales más amplias" (p. 6). Para Arribas (2007), la analogía entre crecimiento económico y desarrollo invierte erróneamente la relación fundamental entre ambos conceptos. El crecimiento económico deja de ser un medio que favorece las condiciones para el desarrollo y se convierte en el fin único a perseguir. De este modo, las capacidades humanas no se desarrollan a medida que se establecen condiciones favorables para ello, sino que se agotan en la persecución misma del crecimiento. Al trastocar esta relación meramente instrumental, corremos como el asno tras la zanahoria que cuelga de un palo ante su hocico: sin saber que la zanahoria, como el crecimiento, no es una meta fija, de modo que siempre estamos corriendo hacia ninguna parte.

En la historia han existido tres grandes momentos en términos de demanda social y oferta natural. Al principio, cuando comenzó a desarrollarse la humanidad, la demanda social por recursos naturales era muchísimo menor que la oferta natural; con el tiempo el crecimiento poblacional y el desarrollo de un sistema cultural contribuyeron a que ambas, demanda social y oferta natural, se igualaran. Sin embargo, hoy día, a pesar de contar con tecnología de punta y el desarrollo de las ciencias, el crecimiento económico y poblacional y la falta de una cultura ambiental han contribuido a que la demanda social por recursos haya sobrepasado la oferta natural, pasando los límites de los sistemas naturales. Como respuesta a ello y producto del Informe Brundtland se empezó a acuñar y conceptualizar el desarrollo sostenible. El concepto de desarrollo sostenible surge como respuesta al intento de articular el modelo económico capitalista a la esfera ambiental. Es decir, buscar un equilibrio entre el sistema de producción capitalista y la capacidad regenerativa y los límites ecológicos de los sistemas naturales. La causa mayor del deterioro continuo del ambiente global es el insostenible modelo de producción y consumo, particularmente en los países industrializados. En tanto que en los países en desarrollo la pobreza y la degradación ambiental están estrechamente interrelacionadas" (Jiménez, 1996).

El Informe Brundtland (1988), elaborado para las Naciones Unidas luego de la Comisión Mundial de Ambiente y Desarrollo celebrada en Tokio en 1987, evidenció en síntesis los problemas ambientales globales y propuso una serie de medidas que debían ser atendidas para revertir el proceso. En este documento se menciona por primera vez el concepto de desarrollo sostenible, en los siguientes términos: "Aquél que satisface las necesidades del presente sin comprometer las necesidades de las futuras generaciones". Realmente el desarrollo sostenible es mucho más que satisfacer las necesidades del presente sin comprometer las de las futuras generaciones; el desarrollo sostenible implica una triple relación de equilibrio constante entre las tres esferas del ambiente: ecológica, social y económica. Tal relación debe ser, por una parte: (I) Viable entre la esfera ecológica y económica, es decir, que pueda existir un equilibrio entre la capacidad regenerativa de los ecosistemas y la demanda de materias primas para generar procesos productivos; (2) Que la sociedad no ejerza presión sobre los ecosistemas e implemente un manejo racional de los recursos naturales; que se implemente una cultura amigable con el ambiente para no llevar los ecosistemas a sus límites, entonces se estaría hablando de un soporte entre las esferas social y ecológica; (3) Por último, debe haber una distribución equitativa de la riqueza, con el fin de disminuir la inmensa brecha entre ricos y pobres. Unos pocos son dueños de grandes riquezas en este planeta, mientras que la gran mayoría de la población mundial muere por hambre, necesidades básicas insatisfechas y enfermedades, entre otros factores. 


\section{Tendencias en educación ambiental no formal}

Pese a que a nivel mundial existe una marcada tendencia a desarrollar procesos de educación ambiental formal, es decir, conducente a títulos, con contenidos curriculares y metodologías definidas y una estructura académica menos flexible. También se data de experiencias muy significativas a nivel comunitario en educación ambiental no formal, con el fin de cambiar actitudes y comportamientos negativos a positivos por parte de los individuos hacia el medio. Países latinoamericanos como Cuba, México, Perú, Costa Rica y España, entre otros, han implementado procesos referentes a la educación ambiental no formal. En el mismo sentido, Cid (2005) manifiesta que entre los resultados obtenidos en el estudio Educación, comunicación e interpretación en los espacios naturales protegidos: El caso de los humedales RAMSAR en España, está que solo un 15\% de los casos analizados manifiesta la voluntad de entender los programas de educación ambiental como instrumento para la gestión de los humedales, un 75\% de los programas para la conservación de los humedales se centra solamente en la divulgación de valores ambientales y tan solo un 10\% señala como objetivos de los programas la participación en la conservación de los espejos de agua. Se percibe entonces, con base en los datos proporcionados por Cid, que la educación ambiental no formal debe dirigirse no solo hacia la divulgación de valores ambientales sino a involucrar a la comunidad en el proceso de conservación de los humedales, al empoderamiento de tales procesos.

Sánchez et al. (2009) aplicaron un enfoque social para el diagnóstico de la cuenca del río San Diego (Cuba), sus resultados abarcaron la identificación de dificultades sociales así como la creación de talleres comunitarios y de una propuesta de educación ambiental, entre otros aspectos. Trellez (2004) desarrolló una secuencia metodológica participativa y prospectiva e incluyó la aplicación del método de escenarios de la Prospectiva Francesa, ${ }^{5}$ en fusión con procesos educativos ambientales con comunidades andinas de Perú. Por su parte, Zamora (2004) analizó la percepción de los usuarios de uno de los parques naturales de Costa Rica, el INBioparque. Se utilizó la técnica de Grupo Nominal'. Esta metodología resultó muy adecuada porque permitió priorizar las necesidades, fortalezas y debilidades del parque como un espacio educativo-recreativo. Agoglia (2004) abordó la problemática socio-ambiental de una comunidad de Puente de Hierro en Mendoza, Argentina, en términos de desarrollo comunitario. Se enfocó en el análisis del proceso socio-ambiental complejo, en el cual se desarrolla el problema de la desnutrición en esa comunidad rural argentina. Se partió del supuesto de que la implementación de una iniciativa educativo-ambiental abordada desde una perspectiva comunitaria ${ }^{7}$ contribuiría al diseño de estrategias de acción y a la gestación de proyectos que dieran respuesta a las problemáticas socio-ambientales de la comunidad de referencia.

Hoy día la educación ambiental no formal se está implementando en diferentes grupos sociales y por lo general a escalas locales. Este instrumento de la gestión ambiental se ha involucrado en procesos que van desde el diagnóstico de microcuencas y protección y conservación de humedales hasta su aplicación como herramienta de la percepción de los usuarios de parques naturales, entre muchos otros ejemplos. Sin embargo, también se pueden señalar ciertos aspectos o factores que no favorecen el desarrollo de procesos no formales en educación ambiental eficientes, como son: (I) indefinición de los límites de una nueva visión ambiental del desarrollo sostenible; (2) escasa participación de las comunidades de carácter renovador hacia el cambio; (3) consolidación limitada de grupos de presión ambiental a nivel local y regional que influyan en el transcurso de los acontecimientos que conducen a la solución de problemas del ambiente; (4) escasa contextualización de alternativas de desarrollo; (5) falta de una significación ambiental clara de las experiencias de la EANF en los países latinoamericanos; (6)

5 Método que permite, partiendo de un conocimiento del presente, establecer una visión sobre lo que se quiere ser en un futuro, junto con las barreras existentes para alcanzarlo. Por la planificación prospectiva participativa, los pueblos y los territorios pueden librarse de los vaivenes del azar y construir el futuro que desean.

6 Técnica creativa utilizada para facilitar la generación de ideas y el análisis de problemas.

7 La perspectiva comunitaria explica cómo los individuos se ven influidos por la gente, las instituciones sociales, las fuerzas sociales que les rodean y cómo los agentes externos son los causantes de la formación de una conducta desadaptada. 
cumplimiento de programas de EANF como requisito para alcanzar metas gubernamentales de las organizaciones, (7) diseño e implementación de programas de EANF descontextualizados, que no responden a las particularidades de los territorios; (8) poco empoderamiento por parte de la comunidad; (9) acciones que no se encaminan hacia el ámbito de la EANF como procesos capaces de generar innovación social y económica; (I0) educación ambiental bajo un enfoque unitario de herramienta de la gestión ambiental y no como pilar de transformación de paradigmas mentales para una comunidad en determinado territorio; (I I) educación ambiental que no se percibe como estrategia para mejorar la gobernabilidad, el ordenamiento y uso eficiente de los territorios; (12) apatía por parte de miembros de las comunidades para participar en los procesos, priorizan incentivos económicos para integrarse a los procesos de EANF; (I3) desconocimiento de las comunidades de los beneficios que pueden obtener participando en procesos educativos ambientales no formales; (14) falta de apoyo por parte de las corporaciones ambientales para generar verdaderos procesos de educación ambiental no formal y (I5) desconocimiento por parte de las corporaciones ambientales y de las comunidades en general de lo que es un verdadero proceso de educación ambiental -por lo general suelen asociarlo a actividades lúdicas y de cualificación-.

\section{La educación ambiental no formal: elementos a considerar para la generación de un modelo}

En términos de la generación de un modelo no formal de educación ambiental, independientemente del fin que persiga, deben existir ciertos elementos fundamentales en su estructuración que permitan su contextualización (ver figura 3). Entre los posibles elementos a considerar se puede señalar la evaluación o diagnóstico a profundidad del territorio y las comunidades que lo habitan; es necesario tener conocimiento de las variables ambientales del área de estudio, incluyendo aspectos socioeconómicos de la población, problemática ambiental y percepción de los individuos acerca del ambiente. El análisis de cada uno de los factores arriba mencionados permitirá establecer el perfil ambiental del territorio,

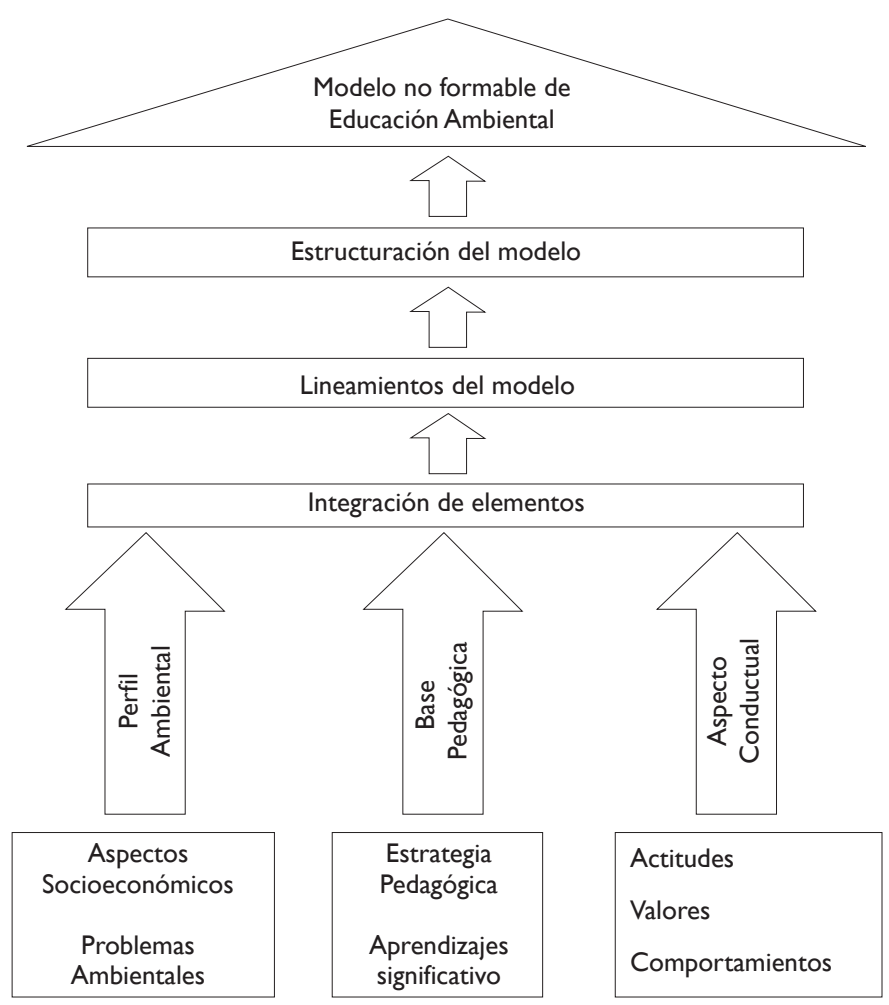

Figura 3. Elementos a considerar para la generación de un modelo no formal de educación ambiental. Fuente: Elaboración propia. 
identificando las debilidades, fortalezas, amenazas y oportunidades que posea. A partir del análisis desarrollado se puede establecer el nivel educativo de las personas, sus ingresos económicos, problemas ambientales, sus causas y efectos, entre otros. Una vez definidos tales lineamientos, es fundamental construir una base pedagógica acorde con las necesidades de enseñanza-aprendizaje de la población o poblaciones con las que se pretenda trabajar; generar aprendizajes significativos en los procesos pedagógicos facilita la comprensión de lo ambiental en los individuos, es decir, un aprendizaje que despierte el interés del individuo. Para Ausubel (1963), "El aprendizaje significativo es el mecanismo humano por excelencia para adquirir y almacenar la inmensa cantidad de ideas e informaciones representadas en cualquier campo de conocimiento" (p. 58). En el mismo sentido, el análisis del aspecto conductual de los individuos en determinado territorio contribuirá a establecer el nivel de concienciación que poseen, mediante el estudio de los valores, actitudes y comportamientos con el entorno donde se desarrollan, los cuales podrían llegar a ser de tipo positivo o negativo. La observación de tales comportamientos sirve de derrotero para mejorarlos; las estrategias, técnicas e instrumentos que se utilicen dependerán del tipo de población con la que se quiera trabajar.

\section{Conclusiones}

Es necesario que la humanidad empiece a pensar en un nuevo modelo económico que sea favorable para el planeta. Desde la perspectiva del fortalecimiento de la autogestión comunitaria, la educación ambiental no formal y participativa debe estar orientada a mejorar y desarrollar esta capacidad de acción comunitaria para resolver sus problemas. Este hecho le atribuye a las comunidades determinadas responsabilidades y funciones, pero al mismo tiempo las capacita para intervenir en el diseño de su propio futuro, situación que las convierte en sujetos de su propio desarrollo. Por lo tanto:

La educación ambiental no formal no debe verse como un simple instrumento de la gestión ambiental, sino como una herramienta de desarrollo e innovación social que contribuye a mejorar la calidad de vida de las personas y a la protección y conservación de los diferentes ecosistemas presentes en los territorios. Es necesario crear una conciencia ambiental global y la educación ambiental no formal puede contribuir en gran medida a alcanzar tal meta. El modelo económico capitalista no contribuye a alcanzar un desarrollo sostenible a nivel global, ni siquiera a la sostenibilidad ambiental. Existe un modelo económico que se desarrolla de espalda a los ecosistemas, sin tener en cuenta sus límites y su capacidad regenerativa, lo que ha provocado un desequilibrio ecológico y generado problemas ambientales en todas las escalas geográficas. Se necesita un modelo económico amigable con el ambiente, que tenga en cuenta la capacidad regenerativa de los sistemas naturales así como sus límites. Igualmente, existe diferencias entre crecimiento y desarrollo. El primero está asociado a la agremiación de cosas, materiales, objetos. En cambio, el desarrollo va encaminado a concretar las potencialidades de un territorio, comunidades o individuos. Por otra parte, el consumismo es uno de los efectos del capitalismo salvaje, concretamente de la globalización; los medios de comunicación se han convertido en la herramienta predilecta para bombardeara a las personas con campañas publicitarias masivas que invitan al consumismo sin sentido de bienes, servicios y productos, aumentando la presión sobre los ecosistemas por la demanda de materias primas para satisfacer a los consumidores. Esto ha hecho que la demanda social supere la oferta natural.

Elementos como el perfil ambiental del territorio, la construcción de una base pedagógica que tome en cuenta las particularidades de la población con la que se pretende trabajar, así como el análisis de las conductas ambientales de los individuos, pueden contribuir a generar modelos pedagógicos no formales dinámicos y resilientes, con gran capacidad de adaptación al contexto en que se vayan a implementar. En Latinoamérica, países como México, España, Cuba y Costa Rica, entre muchos otros, ya iniciaron procesos en educación ambiental no formal, trabajando con comunidades, en su mayoría población adulta, con el fin de proteger y conservar los recursos naturales.

\section{Recomendaciones}

La ejecución eficaz de programas de educación ambiental no formal y participativa requiere de un proceso de organización y formación que brinde a las comunidades los recursos, instrumentos y mecanismos para alcanzar la autogestión comunitaria, desarrollar el sentido de pertenencia 
regional y proporcionar los conocimientos y valores específicos que requieren para poner en marcha las propuestas de desarrollo sustentable. De lo anterior se recomienda:

Dotar a las regiones de una estructura conceptual metodológica desde la educación ambiental no formal que contribuya a dar respuesta a las urgentes necesidades y problemas que se tienen en el campo de la capacitación y organización comunitaria, a través de una propuesta pedagógica específica y una didáctica de apropiación de los conocimientos y valores requeridos. Asimismo, generar espacios de recuperación de experiencias para que, con la participación de las instituciones y organizaciones más representativas, se puedan aprovechar los conocimientos adquiridos por todos ellos y utilizarlos en el desarrollo regional, así como también establecer un sistema de multiplicadores comunitarios que permita aplicar propuestas pedagógicas en grupos prioritarios, a fin de promover la capacitación integral, el intercambio de experiencias, la recuperación crítica y la sistematización de experiencias, la transferencia de tecnologías y el avance de los procesos socioproductivos, con un enfoque de construcción y apropiación del conocimiento y participación dentro de un proyecto de vida comunitario.

Consolidar y establecer organizaciones comunitarias mediante la aplicación de una propuesta pedagógica, con énfasis en la capacitación integral aplicada a los diferentes grupos prioritarios y apoyándose en las alternativas operativas de los programas de capacitación. Además, mejorar las condiciones y la calidad de vida de las comunidades, a través de la implementación de modelos o programas de educación ambiental no formal que les brinden la oportunidad de adquirir conocimientos prácticos y desarrollar sus propios proyectos, desarrollar su capacidad productiva y mejorar los ingresos familiares, hábitos de consumo e higiene, dinamizando su participación en procesos de desarrollo sostenible

\section{Bibliografía}

Agoglia, O. (febrero, 2004). La educación ambiental como proyecto comunitario. La estrategia educativa implementada en la Comunidad de Puente de Hierro. Organismo Autónomo Parques Nacionales. Recuperado de http://www.oei.es/ decada/portadas/nuevas_tendencias.pdf.
Arribas, F. (septiembre, 2007). La idea del desarrollo sostenible. Revista sistemas, (196), 75-86. Recuperado de http://www. ficad.org/lecturas/adicional_uno_unidad_tres_gads.pdf

Ausubel, D (1963). The psychology of meaningful verbal learning. NY: Grune and Stratton.

Brundtland, G. et al. (1988). Nuestro Futuro Común. Madrid: Alianza.

Buenfil, B. \& Rosa, N. (199|). Análisis del discurso y educación en México. México: CINVESTAV.

Camors, J. (agosto, 2009). Educación No Formal Política educativa del MEC 2005-2009. En Aportes para la elaboración de propuesta de políticas educativas. Recuperado de http:// www.oei.es/pdf2/aportes_educacion_no_formaluruguay.pdf

Cid, O. (octubre, 2005). Educación, comunicación e interpretación en los espacios naturales protegidos: El caso de los humedales RAMSAR en España. En Organismo Autónomo Parques Nacionales (Ed.). Nuevas Tendencias en Investigaciones en Educación Ambiental. Recuperado de http://www.oei.es/decada/portadas/nuevas_tendencias.pdf

Covas, О. (2004). La educación ambiental a partir de tres enfoques: Comunitario, sistémico e interdisciplinario. Revista Iberoamericana de Educación, 34, 1-7. http:// www.rieoei.org/rie_contenedor.php? numero=edu_ amb5\&titulo=Educaci\%F3n\%20Ambiental\%20a\%20 partir\%20de\%20tres\%20enfoques:\%20comunitario,\%20 sist\%E9mico\%20e\%20interdisciplinario

González, E. (1993). Hacia una estrategia nacional y plan de acción de educación ambiental. México: INE, UNESCO, SEDESOL.

Guier, E., Rodríguez, M. \& Zúñiga, M. (2002). Educación Ambiental en Costa Rica: Tendencias Evolutivas, Perspectivas y Desafios. San José: EUNED. 99 pp.

Jiménez H., L. M. (1996) Desarrollo sostenible y Economía Ecológica. Integración medio ambiente-desarrollo y economíaecología. Madrid: Editorial Síntesis.

Meira, P. (marzo, 2006). Crisis ambiental y globalización: Una lectura para educadores ambientales en un mundo insostenible. Revista trayectorias, 8(20-21), I|0-123. Recuperado de http://www.redalyc.org/articulo.oa?id=607 | 52480 | |

Novo, M. (1998) La educación ambiental: bases éticas, conceptuales y metodológicas. Madrid: Editorial Universitas.

Novo, M. (septiembre, 2005). Educación ambiental y educación no formal: Dos realidades que se realimentan. Revista de educación, 338, 145-165. Recuperado de http://www.revistaeducacion.mec.es/re338/re338_10.pdf

Organización de las Naciones Unidas para la Educación, la Ciencia y la Cultura (UNESCO) \& Ministerio de Educación y Cultura de Uruguay (MEC). (2009). Aportes para la elaboración de propuestas de políticas educativas. Recuperado de http://www.oei.es/pdf2/aportes_educacion_no_formaluruguay.pdf

Pacheco, F (s. f.). Educación no formal: Conceptos básicos en educación ambiental. Recuperado de http://comenio.files. wordpress.com/2007/08/noformal.pdf 
Sánchez, A., Reyes, L. \& Cruz, J. (diciembre, 2009). Enfoque social en el diagnóstico ambiental de la cuenca del río San Diego. Revista sociedad de la información, 18, 1-12. Recuperado de http://www.sociedadelainformacion.com/ / 8/Enfoque.pdf

Trellez, E. (octubre, 2004). Estudio Prospectivo Sistémico de Situaciones Ambientales como parte de Procesos de Educación Ambiental Participativa: Experiencia con Comunidades Andinas del Perú. En Organismo Autónomo Parques Nacionales (Ed.). NuevasTendencias en Investigaciones en Educación Ambiental. Recuperado de http://www.oei.es/ decada/portadas/nuevas_tendencias.pdf.

Trilla, J. (1996). La educación fuera de la escuela. Barcelona: Ariel.

Zamora, N. (octubre, 2004). El INBioparque como un espacio educativo-recreativo para la conservación de la biodiversidad. Análisis de la percepción de usuarios. En Organismo Autónomo Parques Nacionales (Ed.). Nuevas Tendencias en Investigaciones en Educación Ambiental. Recuperado de http://www.oei.es/decada/portadas/nuevas_tendencias.pdf. 